\title{
Why don't health care workers in France trust the COVID-19 vaccine?
}

\author{
Eric Revue $^{1} \cdot$ Xavier Eyer $^{1} \cdot$ Anthony Chauvin ${ }^{1,2}$ (1)
}

Received: 26 April 2021 / Accepted: 17 June 2021 / Published online: 28 June 2021

(c) The Author(s), under exclusive licence to Canadian Association of Emergency Physicians (CAEP)/ Association Canadienne de Médecine d'Urgence (ACMU) 2021

Keywords Emergency medicine $\cdot$ Health care workers $\cdot$ Vaccination $\cdot$ SARS-CoV-2

\section{Dear Editors,}

The emergence of vaccines, particularly with the development of messenger RNA technology, is a new hope in the battle against COVID-19 [1]. Unfortunately, it seems that there is a lot of mistrust of the vaccine among health care workers. This situation is particularly acute in France. In April 2021, only $51 \%$ of the French medical health workers had received a first dose of vaccine, and only $25 \%$ had received both doses [2]. These data are in contradiction with a survey of 2512 caregivers carried out in in March/April 2020 showing that $81.5 \%$ of them said that they wanted to get vaccinated [3]. How can we explain this mistrust of vaccination that is still so pervasive in emergency departments and among health workers fighting against COVID-19 after a 1-year battle? [4]

Since the first COVID-19 cases, disinformation has spread widely through traditional media and social media, called an "infodemic" by the World Health Organization (i.e., excessive amounts of misinformation and rumors that make it difficult identify reliable sources of information) [5]. Moreover, social media and media gave the opportunity to the conspiracy plot and some eminent famous physician "experts" gave their opinion against the government's strategy [6]. The mistrust of French population has begun to increase as a result of ethical questions or scientific debates about effectiveness of medicines (i.e., hydroxychloroquine, Zinc) as many contradictory studies (not randomized controlled trials) have not given a strong strategy for treating

Eric Revue

eric.revue@aphp.fr

1 Emergency Department and PreHospital EMS (SAMU of Paris) Lariboisière's Hospital, Assistance Publique Hôpitaux de Paris, Paris University, 2 rue Ambroise Paré, 75010 Paris, France

2 Inserm U942 MASCOT, Université de Paris, Paris, France patients [7]. The pandemic has broken the barrier between medical and policy as expressed in recent studies [8].

The main concern of French-speaking health care workers (France, Belgium and Quebec) about the COVID-19 vaccines seems to be the ability to develop them in one year, especially those based on genetic technology [4]. On the other hand, in Europe and particularly in France, a negative attitude towards vaccines has existed and has persisted for many years [9]. An anti-vax community has developed with influential health professionals in their ranks. Thus, each publication on vaccine side effect or policy decisions to stop the use of some vaccines (e.g., AstraZeneca) feeds suspicion, even among health professional $[8,10]$. This is probably one of the reasons why, although vaccination may be thought to play a fundamental role in the prognosis of the population, and even if it is strongly recommended, it is not mandatory.

Thus, we could sum up that, in France, health workers' mistrust of the immunization process is secondary to political issue, new vaccines and low-level scientific debates. We think that French experience of vaccination is not isolated, and no country is immune from a rise in mistrust. In the face of uncertainty about the evolution of the pandemic, pedagogy and transparency of information must be the key points of a global treatment strategy. In the case of health workers, because they are recognized to be at high risk of infection in the workplace, vaccination rate of these personnel must be exemplary [11]. Therefore, their personal and professional responsibility is at the forefront.

\section{Declarations}

Conflict of interest The authors declare that they have no competing interests. 


\section{References}

1. Creech CB, Walker SC, Samuels RJ. SARS-CoV-2 vaccines. JAMA. 2021;325(13):1318-20. https://doi.org/10.1001/jama. 2021.3199.

2. Ministère ds solidarités et de la santé. Liste de diffusion DGSUrgent - Service pour les professionnels de la santé. https://solid arites-sante.gouv.fr/professionnels/article/dgs-urgent. Accessed 19 May 2021.

3. Detoc $M$, Bruel $S$, Frappe $P$, et al. Intention to participate in a COVID-19 vaccine clinical trial and to get vaccinated against COVID-19 in France during the pandemic. Vaccine. 2020;38(45):7002-6. https://doi.org/10.1016/j.vaccine.2020.09. 041.

4. Verger P, Scronias D, Dauby N, et al. Attitudes of healthcare workers towards COVID-19 vaccination: a survey in France and French-speaking parts of Belgium and Canada, 2020. Euro Surveill. 2021;26(3):2002047. https://doi.org/10.2807/1560-7917.ES. 2021.26.3.2002047.

5. Rosenberg H, Syed S, Rezaie S. The twitter pandemic: the critical role of twitter in the dissemination of medical information and misinformation during the COVID-19 pandemic. CJEM. 2020;6:1-4. https://doi.org/10.1017/cem.2020.361.

6. Islam MS, Kamal AHM, Kabir A, et al. COVID-19 vaccine rumors and conspiracy theories: the need for cognitive inoculation against misinformation to improve vaccine adherence. PLoS ONE. 2021;16(5): e0251605. https://doi.org/10.1371/journal.pone. 0251605.

7. Axfors C, Schmitt AM, Janiaud P, et al. Mortality outcomes with hydroxychloroquine and chloroquine in COVID-19 from an international collaborative meta-analysis of randomized trials. Nat Commun. 2021;12:2349. https://doi.org/10.1038/ s41467-021-22446-z.

8. Navarro JA, Markel H. Politics, pushback, and pandemics: challenges to public health orders in the 1918 influenza pandemic. Am J Public Health. 2021;111(3):416-22. https://doi.org/10.2105/ AJPH.2020.305958.

9. Larson HJ, de Figueiredo A, Xiahong Z, et al. The state of vaccine Confidence 2016: global insights through a 67-country Survey. EBioMedicine. 2016;12:295-301. https://doi.org/10.1016/j. ebiom.2016.08.042.

10. Euronews. How have different Eurpoean countries reacted to the astrazeneca vaccine doubts? https://www.euronews.com/2021/04/ 20/how-have-different-european-countries-reacted-to-the-astra zeneca-vaccine-doubts. Accessed 9 Jun 2021.

11. Smith P. COVID-19 in Australia: most infected health workers in victoria's second wave acquired virus at work. BMJ. 2020;27(370): m3350. https://doi.org/10.1136/bmj.m3350. 